Wright State University

CORE Scholar

8-2013

\title{
Combat Disclosure in Intimate Relationships: Mediating the Impact of Partner Support on Posttraumatic Stress
}

\author{
Christina Balderrama-Durbin \\ Douglas K. Snyder \\ Jeffrey A. Cigrang \\ Wright State University, jeffrey.cigrang@wright.edu \\ G. Wayne Talcott \\ JoLyn Tatum
}

See next page for additional authors

Follow this and additional works at: https://corescholar.libraries.wright.edu/sopp

Part of the Psychology Commons

\section{Repository Citation}

Balderrama-Durbin, C., Snyder, D. K., Cigrang, J. A., Talcott, G. W., Tatum, J., Baker, M., Cassidy, D., Sonnek, S., Heyman, R. E., \& Smith Slep, A. M. (2013). Combat Disclosure in Intimate Relationships: Mediating the Impact of Partner Support on Posttraumatic Stress. Journal of Family Psychology, 27 (4), 560-568. https://corescholar.libraries.wright.edu/sopp/36

This Article is brought to you for free and open access by the School of Professional Psychology at CORE Scholar. It has been accepted for inclusion in School of Professional Psychology Faculty Publications by an authorized administrator of CORE Scholar. For more information, please contact library-corescholar@wright.edu. 


\section{Authors}

Christina Balderrama-Durbin, Douglas K. Snyder, Jeffrey A. Cigrang, G. Wayne Talcott, JoLyn Tatum, Monty Baker, Daniel Cassidy, Scott Sonnek, Richard E. Heyman, and Amy M. Smith Slep 


\title{
Combat Disclosure in Intimate Relationships: Mediating the Impact of Partner Support on Posttraumatic Stress
}

\author{
Christina Balderrama-Durbin and Douglas K. Snyder \\ Texas A\&M University \\ G. Wayne Talcott \\ University of Tennessee Health Science Center
}

\author{
Monty Baker, Daniel Cassidy, and Scott Sonnek \\ Lackland AFB, San Antonio, Texas
}

\author{
Jeffrey Cigrang \\ Wright-Patterson AFB, Dayton, Ohio \\ JoLyn Tatum \\ Wright-Patterson AFB, Dayton, Ohio \\ Richard E. Heyman and Amy M. Smith Slep \\ New York University
}

\begin{abstract}
Although previous research has shown a negative relation between partner support and posttraumatic stress disorder (PTSD) symptom severity among military service members following deployment, the mediating mechanisms of this effect remain poorly understood. This study examined willingness to disclose deployment- and combat-related experiences as a mediating mechanism underlying the linkage between intimate partner support and PTSD symptom severity in a sample of 76 U.S. Air Force service members deployed to Iraq in a year-long, high-risk mission. Airmen's reports of overall social support, and partner support specifically, significantly predicted concurrent postdeployment PTSD symptom severity. Subsequent mediation analyses demonstrated that level of disclosure of deployment- and combat-related experiences by service members to their intimate partners accounted for a significant portion of the relation between partner support and postdeployment PTSD symptom severity. The level of Airmen's disclosure was also inversely related to levels of relationship distress. Implications of these findings for prevention and intervention strategies and for further research are discussed.
\end{abstract}

Keywords: posttraumatic stress, social support, partner support, combat disclosure, intimate relationships

Since the terrorist attacks on the United States on September 11, 2001, over 2 million American service members have been mobilized to Iraq and Afghanistan in Operations Iraqi Freedom (OIF) and Enduring Freedom (OEF). This sustained mobilization, the

This article was published Online First June 17, 2013.

Christina Balderrama-Durbin and Douglas K. Snyder, Department of Psychology, Texas A\&M University; Jeffrey Cigrang, Wright-Patterson Air Force Base, Dayton, Ohio; G. Wayne Talcott, Department of Preventative Medicine, University of Tennessee Health Science Center; JoLyn Tatum, Wright-Patterson Air Force Base; Monty Baker, Daniel Cassidy, and Scott Sonnek, Wilford Hall Ambulatory Surgical Center, Lackland Air Force Base, San Antonio, Texas; Richard E. Heyman and Amy M. Smith Slep, Department of Cariology and Comprehensive Care, New York University.

This article is based off of data used in a dissertation study by the primary author. The views expressed in this article are those of the authors and do not reflect the official policy or position of the Department of the Air Force, Department of Defense, or the U.S. Government. This work was supported in part by an award from the Military Operational Medicine Research Program, U.S. Army Medical Research and Materiel Command, to Jeffrey Cigrang.

Correspondence concerning this article should be addressed to Christina Balderrama-Durbin, Texas A\&M University, Department of Psychology Mailstop 4235, College Station, TX 77843-4235. E-mail: balderramadurbin@neo.tamu.edu largest since the Vietnam War, has created unique challenges related to its duration, tempo, and ambiguous combat circumstances. Nearly 800,000 service members have deployed multiple times (Tan, 2009), with relatively short interim periods between deployments, potentially exacerbating the effects of deployment for themselves as well as their family members.

Although many service members and their families demonstrate remarkable resilience in response to the service member's deployment to a combat theater, many others do not. Exposure to combat places a service member at risk for the development of PTSD (Buydens-Branchey, Noumair, \& Branchey, 1990), with prevalence rates of PTSD estimated at $12 \%$ to $20 \%$ for combat soldiers and Marines returning from OIF (Hoge et al., 2004). In a large study of Iraq and Afghanistan veterans receiving Veterans Affairs (VA) health care, $37 \%$ received a mental health diagnosis, $22 \%$ were diagnosed with posttraumatic stress disorder (PTSD), and $17 \%$ with depression (Seal et al., 2009). The effects of PTSD have been shown to extend beyond individual service members to also adversely impact their intimate relationships (Allen, Rhoades, Stanley, \& Markman, 2010; Riggs, Byrne, Weather, \& Litz, 1998).

Previous research has examined a variety of potential risk and protective factors for PTSD. Converging evidence from these studies documents perceived social support as one of the strongest protective factors against PTSD for a variety of trauma-exposed adults including military trauma (for reviews see Brewin, An- 
drews, \& Valentine, 2000; Ozer, Best, Lipsey, \& Weiss, 2003). Specifically, Vietnam veterans with higher levels of social support report better mental and physical health outcomes, including fewer PTSD symptoms, compared with those with lower levels of support (Keane, Scott, Chavoya, Lamparski, \& Fairbank, 1985; Ren, Skinner, Lee, \& Kazis, 1999), even when controlling for premorbid behavioral functioning in areas of family, school, employment, and social history. Furthermore, the maintenance of PTSD was associated with lower social support at homecoming and lower concurrent social support (Schnurr, Lunney, \& Sengupta 2004). More recent research assessing OIF Army National Guard members across the deployment cycle demonstrated that lower perceived social support at postdeployment was associated with the development of PTSD (Polusny et al., 2011). However, although the association between social support and PTSD is well established, the causal directionality of this relation is less clear.

Some recent evidence suggests a bidirectional relation between social support and PTSD. A longitudinal study of natural disaster survivors found that greater social support upon initial impact (in the first 6 to 12 months) led to fewer PTSD symptoms following the disaster. Additionally, postdisaster PTSD symptoms also led to less social support assessed between 12 to 18 months following the disaster (Kaniasty \& Norris, 2008). Social support demonstrates a buffering effect against the impact of trauma, whereas PTSD also appears to erode support networks over time. Benotsch et al. (2000) also found evidence in support of the bidirectional relation between PTSD and social support in Gulf War veterans such that social support at Time 1 predicted PTSD symptoms at Time 2, and PTSD symptoms at Time 1 also predicted social support at Time 2. Other studies did not find evidence for a bidirectional relation between PTSD and social support, particularly when the PTSD is chronic (King, Taft, King, Hammond, \& Stone, 2006; Laffaye, Cavella, Drescher, \& Rosen, 2008). However, despite the evidence indicating social support as a resiliency factor protecting against PTSD following deployment, to date there has been little research examining either the differential benefits of specific forms of social support or-more importantly-the mediating mechanisms of social support for current OEF/OIF veterans.

Spouses and intimate partners often serve as a primary source of social support in adulthood. Over half of all service members are married (U.S. Department of Defense, 2007) and, among nonmarried personnel, many report being in an exclusive intimate relationship lasting 6 months or longer. Marital status is often used (in part or whole) as an index of support, and has been linked to a wide variety of health benefits. However, spouses can also function as sources of stress, rather than support, for combat veterans (Laffaye et al., 2008). Hence, understanding the mechanisms by which resilience to PTSD is imparted through partner support is vital to both prevention and intervention strategies aimed at harnessing the potential benefits of these intimate relationships.

\section{Intimate Relationships and PTSD}

Cross-sectional research has consistently demonstrated a positive association between PTSD symptoms and relationship distress for OEF/OIF soldiers and National Guard members (Allen et al., 2010; Nelson Goff, Crow, Reisbig, \& Hamilton, 2007; Renshaw, Rodrigues, \& Jones, 2008). Moreover, specific symptom clusters or components of PTSD such as dissociation (Nelson Goff et al.,
2007) and numbing or avoidance symptoms (Cook, Riggs, Thompson, Coyne, \& Sheikh, 2004; Erbes, 2011; Renshaw \& Campbell, 2011; Riggs et al., 1998) appear to be associated with greater erosion of relationship functioning. Specific problematic areas of relationship functioning for service members struggling with PTSD and their partners have also been identified. For active duty Army personnel, negative communication, positive bonding, and parenting alliance mediated the relation between PTSD and marital satisfaction (Allen et al., 2010). PTSD avoidance symptoms have also been found to be negatively related to spouses' communication satisfaction (Hendrix, Erdmann, \& Briggs, 1998). Vietnam veterans diagnosed with PTSD reported greater difficulty in selfdisclosure and expressiveness to their partners compared with veterans without PTSD (Carroll, Rueger, Foy, \& Donahoe, 1985). Other research, with ex-prisoner of war Israeli combat veterans, has shown the negative relation between PTSD and marital intimacy to be mediated by the level of self-disclosure to their partners (Solomon, Dekel, \& Zerach, 2008). Overall, convergent evidence from these studies documents the importance of communication, particularly self-disclosure, in veteran populations with PTSD. Although avoidance can be an adaptive coping strategy in limited contexts, evidence suggests that avoidance may be particularly harmful in the context of intimate relationships and in the manifestation of PTSD (Reddy, Meis, Erbes, Polusny, \& Compton, 2011).

Therapeutic interventions from a variety of theoretical perspectives emphasize the importance of disclosure of traumatic experiences and cognitive or behavioral engagement of avoided stimuli. Some research supports the benefits of disclosing traumatic experiences outside of a formalized treatment setting. For military peacekeepers in the United Kingdom, talking about their experiences was associated with less psychological distress, with most turning to peers and family members (Greenberg et al., 2003). Additionally, written expression paradigms have demonstrated beneficial effects of the soldiers' expressive writing on marital satisfaction for active duty soldiers and their spouses (Baddeley \& Pennebaker, 2011).

A service member's disclosure potentially influences the accuracy of a partner's perceptions and attributions regarding the service member's stress reactions postdeployment; in turn, these cognitions may influence the partner's own stress reaction upon reintegration. Renshaw, Rodrigues, and Jones (2008) found that when spouses perceived that their partners had experienced high levels of combat, spouses' marital distress was no longer related to service members' self-reported PTSD symptoms, whereas when spouses perceived low levels of combat, spouses' marital distress was positively related to service members' self-reported PTSD symptoms. That is, attributions linking a service member's PTSD symptoms to combat experiences resulted in an attenuated negative effect on the spouse's own psychological and marital distress. Moreover, spouses' perceptions are particularly important in attenuating the link between relationship distress and avoidance/ numbing symptoms of PTSD (Renshaw \& Campbell, 2011).

Other research suggests that disclosure in some contexts may have adverse effects on traumatized individuals and their partners. A study examining sexual assault survivors demonstrated that negative social reactions in response to disclosure were strongly correlated with PTSD symptoms (Ullman, Townsend, Filipas, \& Starzynski, 2007). That is, self-disclosure in an unsupportive or 
distressed intimate relationship may promote further negative impact on the traumatized individual, suggesting the importance of assessing the interpersonal context of the disclosure.

Therapeutic interventions for PTSD attempt to resolve past trauma by no longer allowing the traumatized individual to avoid traumatic thoughts and feelings and facilitating cognitive and emotional processing of the traumatic event (Foa, Hembree, \& Rothbaum, 2007; Resick \& Schnicke, 1992). One way of initiating cognitive and emotional processing of traumatic combat-related experiences is through disclosure of these experiences in an empathic and supportive relational environment. Recent work by Monson and colleagues has shown improvement in individual and relationship functioning for combat veterans receiving cognitivebehavioral conjoint therapy for PTSD that focuses on eliciting the soldiers' disclosure of traumatic events and partners' empathic responding to facilitate dyadic cognitive restructuring and decrease behavioral avoidance (Fredman, Monson, \& Adair, 2011; Monson, Fredman, \& Adair, 2008). In this approach, explicit renditions of the traumatic event are discouraged (Fredman et al., 2011). Alternative couple therapy approaches such as integrative behavioral couple therapy have been applied to PTSD (Erbes, Polusny, MacDermid, \& Compton, 2008) to encourage limited disclosure of combat experiences without delving into systemic exposure in a couple context. Both therapeutic approaches advise against disclosure of the "gory details," in part, to avoid the potential for eliciting a secondary stress response. A recent study of Vietnam veterans demonstrated that communication about deployment experiences was unrelated to their partners' psychological distress when the veteran did not have clinically significant PTSD symptoms, but was significantly related to the partners' distress when veterans endorsed clinically significant PTSD (Campbell \& Renshaw, 2012).

Despite the development of various therapeutic approaches promoting the disclosure of traumatic experiences, the majority of OEF and OIF soldiers who screen positive for a mental illness do not seek professional mental health treatment (Hoge et al., 2004). That is, service members returning from combat often turn to others in their social support network to discuss experiences and consequences of combat outside of a therapeutic context. Indeed, because nearly half of veterans seeking outpatient mental health treatment for PTSD report that a health care provider was not the first person to whom the veteran disclosed his or her trauma (Leibowitz, Jeffreys, Copeland, \& Noël, 2008), the role of significant others in providing a supportive context for disclosure of traumatic experiences may be particularly critical in promoting protection from PTSD and related adverse outcomes.

The current investigation sought to assess the impact of disclosure of deployment- and combat-related experiences in the relation between partner support and PTSD symptoms for U.S. Air Force Security Force active duty members following a year-long, high risk deployment to Iraq. The direct concurrent association between perceived social support, and specifically partner support, and PTSD symptoms was evaluated 6- to 9 months postdeployment. Additionally, the service member's willingness to disclose deployment- and combat-related experiences to his or her intimate partner was also assessed as a potential mediating mechanism by which partner support lends its greatest benefit in resiliency following deployment- and combat-related trauma. Similar to a mediational model proposed by Hoyt et al. (2010), it was hypothe- sized that the service member's willingness to disclose deployment- and combat-related experiences would serve as the primary mechanism by which partner support attenuates the experience of PTSD symptoms. Because other intrapersonal and interpersonal factors such as the number of combat experiences encountered during deployment and the level of relationship distress may potentially influence the level of comfort with disclosure to one's intimate partner, these contextual factors were also assessed. Both relationship distress and the number of combat experiences are highly related to PTSD symptoms; additionally, in postdeployment focus group discussions from the current sample, service members qualitatively reported that relationship quality and the nature of specific combat experiences influence their willingness to discuss their deployment experiences with their partner (Cigrang et al., 2011). Hence, the following corresponding hypotheses were evaluated:

Hypothesis 1: There will be negative relations between both overall perceived social support and perceived partner support and service members' symptoms of PTSD.

Hypothesis 2: The negative relation between perceived partner support and PTSD symptoms will be partially mediated by the willingness to disclose thoughts and feelings related to deployment- and combat-related experiences to one's intimate partner, such that a mechanism by which partner support is related to lower levels of PTSD symptoms is through higher levels of combat disclosure.

Hypothesis 3: Relationship distress will be negatively related to the service member's level of combat disclosure to his or her partner.

Hypothesis 4: Additionally, the number of combat experiences encountered during deployment will be negatively related to the service member's level of combat disclosure to his or her partner.

\section{Method}

\section{Participants and Procedures}

Participants were a subset of active-duty service members from a larger longitudinal investigation of U.S. Air Force Security Forces. The original investigation assessed a variety of risk and protective factors across a year-long deployment to Iraq (Cigrang et al., 2011). Two detachments of Airmen (combined $n=318$ ) were tasked to train Iraqi police, a high-risk mission that required patrolling in communities with insurgent fighters; they deployed in two consecutive, 1-year deployment cycles during 2009 and 2010. They were assessed at three time points in the deployment cycle: predeployment, in-theater, and postdeployment. Partner support and combat disclosure were only assessed postdeployment. A total of 196 Airmen voluntarily participated in the follow-up assessment at 6- to 9-months postdeployment. Of these service members, 112 Airmen reported being in a committed relationship lasting 6 months or longer at predeployment and were followed across the deployment cycle. Of those partnered Airmen, 76 remained in the same committed relationship across the entirety of the deployment cycle and were included in the current investigation. The current 
sample excluded any romantic relationships that had ended in divorce $(n=24)$ or had taken steps to end the relationship after deployment $(n=12)$. These Airmen were removed because of their reduced opportunity for disclosure with their partners, thereby potentially biasing results and implications for the current findings. As expected, an independent samples $t$ test revealed that the participants who were separated or divorced engaged in significantly less combat disclosure with their partner, $t(93)=2.51$, $p<.05$, compared with those who remained together across the deployment cycle.

Of the 76 partnered Airmen, the majority (92\%) were male with an average age of 27.9 years $(S D=6.1$, range $=21-42)$. The mean years of education was $13.7(S D=1.8$, range $=12-20)$, with over half $(60 \%)$ of the service members graduating from high school or earning a GED or higher. The average duration of all prior deployments combined was 13.1 month $(S D=7.3$, range $=$ 1-30), with a mean of 13.9 months since the last deployment $(S D=8.2$, range $3-39)$. Nearly half of the Airmen $(46 \%)$ had deployed at least twice previously in an OEF/OIF mission. A majority $(66 \%)$ of participants were Caucasian, followed by $14 \%$ African American, 11\% Hispanic, 5\% Asian, and 2\% Native American.

\section{Measures}

PTSD. The PTSD Checklist-Military version (PCL-M) is a 17-item measure corresponding to the 17 symptoms of PTSD outlined in the Diagnostic and Statistical Manual of Mental Disorders (DSM-IV, American Psychiatric Association, 1994). Items also correspond to the three clusters of PTSD: reexperiencing, avoidance/numbing, and hyperarousal (Weathers, Huska, \& Keane, 1991). For each item, respondents rate how much they have been "bothered by the problem in the past month" on a 5-point Likert scale from 1 (not at all) to 5 (extremely), with scores ranging from 17-85. The PCL-M demonstrates excellent internal consistency $(\alpha=.96)$, and test-retest reliability ( $r=.96$; Weathers, Litz, Herman, Huska, \& Keane, 1993) and correlates highly with other standardized measures of PTSD (Forbes, Creamer, \& Biddle, 2001). For all Airmen who completed postdeployment measures, the PCL-M demonstrated excellent internal consistency $(\alpha=.95$; mean interitem $r=.55)$. Comparable values $(\alpha=.96$; mean interitem $r=.61$ ) were found for the 76 service members in the same intimate relationship across the deployment cycle included in this study.

Social support. The Multidimensional Scale of Perceived Social Support (MSPSS) is a 12-item measure designed to capture the subjective, perceived adequacy of social support (Zimet, Dahlem, Zimet, \& Farley, 1988) across three sources including family, friends, and significant other. Items are rated on a 7-point Likert scale ranging from 1 (very strongly disagree) to 7 (very strongly agree), with scores ranging from 12-84. Subscales distinguishing among the three sources of social support were supported through factor analysis. The present study used both the overall measure of social support as well as the 4-item subscale specifically targeting support from the Airman's "significant other" or intimate partner. The MSPSS was administered at postdeployment only.

Previous research has supported the 2- to 3-month temporal stability of both the total social support score $(r=.85)$ and "significant other" subscale $(r=.72)$ as well as their internal consistency ( $\alpha=.88$ for the total score and .91 for the "significant other" subscale). The MSPSS has been shown to correlate positively with other measures of social support (Kazarian \& McCabe, 1991), to correlate negatively with measures of depression and anxiety (Zimet, Powell, Farley, Werkman, \& Berkoff, 1990), and to be generally unrelated to measures of social desirability (Kazarian \& McCabe, 1991). For all Airmen in the current study who completed postdeployment measures, the full measure of the MSPSS demonstrated excellent internal consistency $(\alpha=.94$ mean interitem $r=.56)$. Comparable values $(\alpha=.93$; mean interitem $r=.52$ ) were found for the 76 participants in the same intimate relationship across the deployment cycle. Additionally, the 4-items of the "significant other" subscale demonstrated excellent internal consistency ( $\alpha=.93$; mean interitem $r=.79$ ) for the 76 Airmen in a committed relationship.

Combat disclosure. The Combat Disclosure Scale (CDS) is a 6-item self-report measure designed to evaluate a service member's willingness to disclose his or her thoughts and feelings related to deployment- and combat-related experiences to an intimate partner (Balderrama-Durbin et al., 2011). Items are measured on a 4-point Likert scale ranging from 1 (strongly disagree) to 4 (strongly agree), with scores ranging from 6 (no disclosure) to 24 (high disclosure). Three of the six items assess the disclosure of deployment experiences more broadly (e.g., "I avoid discussing deployment experiences with my partner"), whereas the remaining three items assess disclosure of combat-related experiences specifically (e.g., "I find it hard to discuss my feelings related to combat with my partner"). The CDS was administered at postdeployment only. For the 76 Airmen who were in an intimate relationship and completed postdeployment measures, the CDS demonstrated excellent internal consistency $(\alpha=.94$; mean interitem $r=.73$ ).

Relationship distress. The Marital Satisfaction InventoryBrief form (MSI-B) is a 10-item, true-false, screening measure designed to identify intimate relationship distress (Whisman, Snyder, \& Beach, 2009). Two items from each of five scales from the Marital Satisfaction Inventory-Revised (Snyder, 1997) including Global Distress, Time Together, Sexual Dissatisfaction, Affective Communication, and Problem-Solving Communication were selected for this measure based on item-scale correlations. Scores range from $0-10$, with half of the items coded as discordant if answered "true" and half as discordant if answered "false." Using a cut-score $\geq 4$ for discriminating distressed from nondistressed couples, the MSI-B exhibits high sensitivity and specificity $(.87$ and .84 , respectively). In the original standardization sample, the MSI-B had good temporal reliability (6-week $r=.79$ ) and internal consistency $(\alpha=.81$; mean interitem $r=.31)$. For the 76 Airmen in an intimate relationship who completed postdeployment measures in this study, the MSI-B demonstrated high internal consistency $(\alpha=.91$; mean interitem $r=.49)$.

Combat experiences. The Exposure to Combat Scale (ECS) lists 22 stressful experiences that may have occurred during deployment, and was adapted from an 18-item measure previously described by Hoge et al. (2004). Service members indicate whether or not they have experienced a combat-related event (e.g., "being shot at" or "seeing dead or seriously injured Americans"), and also rate the event's emotional impact on a 4-point Likert scale from $1=$ no impact to $4=$ extreme impact. For this study, the number of stressful events experienced served as the measure of interest, 
with scores ranging from $0-22$. Prior research suggests a strong positive relation between combat experiences and PTSD symptomatology following deployment (Hoge et al., 2004). For all Airmen who completed postdeployment measures, the ECS (scored as number of experienced stressful events) demonstrated good internal consistency ( $\alpha=.88$; mean interitem $r=.26)$. Comparable values $(\alpha=.90$; mean interitem $r=.29)$ were obtained for the 76 participants in the same intimate relationship across the deployment cycle.

\section{Results}

Bivariate correlations among variables are shown in Table 1. PTSD symptoms were negatively related to partner support and combat disclosure, and were positively related to relationship distress and number of combat experiences. Partner support was positively related to combat disclosure and was negatively related to relationship distress. Finally, relationship distress was negatively related to combat disclosure (see Table 1).

Prior to conducting mediation analysis, simple regression was used to examine the direct effects of both overall perceived social support (including family, friends, and significant other) on PTSD symptom severity, as well as specific effects of perceived partner support (to compare findings from this sample of 76 service members with previous studies in this domain). Consistent with prior literature (and Hypothesis 1), regression replicated the negative relation between overall social support and PTSD symptom levels in the current sample, $\beta=-.53, t(71)=-5.28, p<.001$. That is, overall social support accounted for $28.2 \%$ of the variance in postdeployment PTSD symptom severity. Moreover, regression analysis confirmed the direct specific effect of perceived partner support on PTSD symptom levels, $\beta=-.36, t(72)=-3.24, p<$ .05 , (see Figure 1), with partner support accounting for $12.7 \%$ of the variance in postdeployment PTSD symptom severity.

\section{Mediation Analysis}

The negative relation between perceived partner support and PTSD symptoms was hypothesized to be partially mediated by the level of disclosure of thoughts and feelings related to deploymentand combat-related experiences to one's intimate partner (Hypothesis 2). The direct effects between each of the variables of interest were examined. As noted earlier, there was an overall negative effect of perceived partner support on PTSD $(\beta=-.36$; see Figure 1). There was also a significant direct effect of perceived partner support on combat disclosure such that greater perceived partner support predicted greater likelihood of disclosing

Table 1

Correlations Among Study Variables

\begin{tabular}{lcccc}
\hline & 1 & 2 & 3 & 4 \\
\hline 1. PTSD symptoms & - & & & \\
2. Partner support & $-.36^{* *}$ & - & & \\
3. Combat disclosure & $-.38^{* *}$ & $.27^{*}$ & - & \\
4. Relationship distress & $.29^{*}$ & $-.51^{* * *}$ & $-.29^{*}$ & - \\
5. Combat experiences & $.37^{* *}$ & -.09 & -.23 & .18 \\
\hline
\end{tabular}

Note. $\mathrm{PTSD}=$ posttraumatic stress disorder.

${ }^{*} p<.05$. ${ }^{* *} p<.01$. (a) Direct Effect

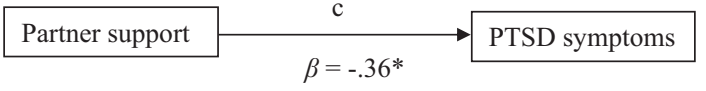

(b) Indirect Effect

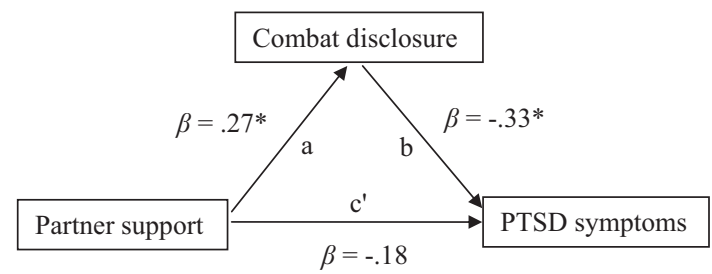

Figure 1. Path models for the direct (a) and indirect (b) effects of partner support on posttraumatic stress disorder (PTSD) symptom severity through combat disclosure. ${ }^{*} p<.05$.

deployment- and combat-related experiences, $\beta=.27, t(64)=$ $2.25, p<.05$. Combat disclosure significantly predicted postdeployment PTSD symptom levels, $\beta=-.33, t(63)=-2.74, p<$ .05 , after controlling for the effects of perceived partner support, $\beta=-.18, t(63)=-1.49, p=.14$, rendering the direct effect of partner support on PTSD (Figure 1a) nonsignificant with the addition of disclosure in the model (Figure 1b), demonstrating at least partial mediation.

To assess the significance of the mediation effect, a bootstrapping method was used to estimate the confidence interval of the indirect effect. Bootstrapping is a nonparametric resampling method that approximates the sampling distribution from the available data. Bootstrapping methods are recommended when either the sample size or predicted effect size is restricted (MacKinnon, Lockwood, \& Williams, 2004). A total of 5,000 iterations of sampling in Mplus (version 6; Muthén \& Muthén, 2010) were used to examine the indirect effect of partner support on PTSD symptoms through the mediating mechanism of combat disclosure. Cases with missing data $(n=8)$ were included and estimated using the Full Information Maximum Likelihood (FIML) procedure. Results demonstrated that the indirect effect of partner support on PTSD through combat disclosure was significant with a $95 \%$ confidence interval of -.90 to -.05 (see Table 2).

Considering the cross-sectional nature of the data, and prior evidence suggesting the bidirectional relation between PTSD and social support, a second competing model was examined using PTSD as a predictor of partner support with combat disclosure as a mediator of this effect. This competing model had poorer model fit $(\mathrm{AIC}=851.90$, compared with $\mathrm{AIC}=1035.81$ from the original model). Additionally, the indirect effect of PTSD on partner support was not mediated by combat disclosure such that the confidence interval contained zero.

\section{Effects of Relationship Distress and Combat Experiences on Disclosure}

Relationship distress and the number of combat experiences were evaluated as relevant contextual factors due to their known association with PTSD symptoms and service members' qualitative reports of their potential impact on their willingness to discuss 
Table 2

Summary of Regression Results Including Both Direct and Indirect Effects

\begin{tabular}{lccc}
\hline & \multicolumn{2}{c}{ Regression results } & \\
\cline { 2 - 3 } \multicolumn{1}{c}{ Path/effect } & $\beta$ & $S E$ & $\begin{array}{c}\text { 95\% Confidence } \\
\text { Interval }\end{array}$ \\
\hline $\mathrm{c}(\mathrm{PS} \rightarrow$ PTSD) & $-.36^{*}$ & .38 & {$[-2.00,-0.48]$} \\
$\mathrm{a}(\mathrm{PS} \rightarrow$ CD) & $.27^{*}$ & .16 & {$[0.04,0.67]$} \\
$\mathrm{b}(\mathrm{CD} \rightarrow$ PTSD) & $-.33^{*}$ & .36 & {$[-1.71,-0.27]$} \\
$\mathrm{c}^{\prime}$ & -.18 & -.18 & {$[-1.64,0.24]$} \\
$\mathrm{a} \times \mathrm{b}$ (indirect effect) & $-.11^{*}$ & .06 & {$[-0.90,-0.05]$} \\
Relationship distress & $-.29^{*}$ & .21 & {$[-0.91,-0.09]$} \\
Combat experiences & -.23 & .12 & {$[-0.47,0.02]$} \\
\hline
\end{tabular}

Note. $\quad$ PS $=$ partner support, PTSD = posttraumatic stress disorder symptom severity, $\mathrm{CD}=$ combat disclosure. Reported confidence intervals are centered around unstandardized regression coefficients. The confidence interval for the indirect effect was estimated using a bootstrapping method while the regression coefficient was estimated using the Sobel test (1982). $* p<.05$.

their deployment experiences with their partner. Both postdeployment relationship distress (as measured by the MSI-B) and the number of combat experiences were expected to be negatively related to the level of combat disclosure (Hypotheses 3 and 4 , respectively). These contextual factors were analyzed separately due to restrictions in power. Regression analyses confirmed that, as hypothesized, greater relationship distress predicted a lower likelihood of combat disclosure by service members to their partners, $\beta=-.29, t(62)=-2.41, p<.05$. Moreover, as the number of combat experiences increased, there was also a nonsignificant trend for participants to engage in less combat disclosure, $\beta=$ $-.23, t(61)=-1.85, p=.07$ (see Table 2$)$.

\section{Discussion}

Although social support has previously been shown to serve as an important postdeployment protective factor buffering the adverse effects of combat exposure and PTSD (Polusny et al., 2011), the mediating mechanisms of social support have not been well explicated. The present study aimed to disentangle the effects attributable to partner support, a specific source of social support, and their underlying mechanisms, potentially contributing to more efficacious prevention and intervention protocols aimed at service members as they return from combat operations and confront diverse challenges of reintegrating into their families or intimate relationships.

Replicating previous findings, in the present study service members' reports of overall social support were significantly related to PTSD symptom severity 6- to 9-months after returning from a year-long high-risk deployment to Iraq, accounting for $28.2 \%$ of the variance in this critical outcome. Moreover, intimate partner support accounted for $12.7 \%$ of the variance in postdeployment PTSD symptoms. Subsequent mediation analyses demonstrated that the willingness to disclose deployment- and combat-related experiences by service members to their intimate partners explained a significant portion of the relation between partner support and postdeployment PTSD symptom severity. Findings suggest that higher levels of partner support may promote a safe context for vulnerable disclosure, and that it is specifically through the disclosure of deployment- and combat-related experiences that the detrimental effects of combat exposure are mitigated after returning from deployment.

Because recent longitudinal research suggests a bidirectional relation between social support and PTSD, additional analyses examined the possibility that PTSD symptoms lead to lower levels of combat disclosure and, hence, reduced opportunity for service members to experience intimate partner support. This reverse mediation model was not supported, lending greater confidence to the primary model despite the cross-sectional nature of the data. Considering these findings as a whole, it is more likely that partner support fosters a safer context for disclosure of combat-related experiences, and that it is through such disclosure that PTSD symptoms are attenuated.

Both relationship distress and the number of combat experiences were also evaluated as contextual factors potentially impacting service members' levels of combat disclosure. As predicted, higher levels of relationship distress were associated with lower levels of combat disclosure. That is, combat disclosure was more likely to occur in a supportive, emotionally safe relationship. Furthermore, there was a tendency for those Airmen who experienced a greater number of traumatic experiences during deployment to engage in less combat disclosure with their partners. Although not reaching statistical significance, this suggests further research exploring at least two possibilities: First, higher exposure to combat may impede disclosure in informal or social relationships because of perceived vulnerability or risk to the service member's own emotional functioning; or, second, service members may be reluctant to disclose higher levels of combat-related trauma in an effort to protect their partners from anticipated reactive distress. Future studies could also examine how different kinds of combat-related experiences, rather than simply their number, might influence the likelihood of postdeployment disclosure. Longitudinal study designs could also clarify the casual relations among combat exposure, PTSD, and combat disclosure.

The benefits of disclosing emotionally difficult experiences have been reliably demonstrated in formal therapeutic settings. For example, interventions for PTSD rely on disclosure of traumatic events to facilitate cognitive and emotional processing of the trauma (Foa et al., 2007; Resick \& Schnicke, 1992). Additionally, recent research demonstrates improvement in individual and relationship functioning for combat veterans receiving cognitivebehavioral conjoint therapy for PTSD that facilitates veterans' disclosure of traumatic events and partners' empathic responding (Monson et al., 2008). Although disclosure and processing of trauma have been demonstrated to be effective in formal treatment settings, the current study suggests that, at least for some, such disclosure is associated with benefits in naturally occurring, supportive intimate relationships.

Important elements regarding disclosure continue to remain unknown. More needs to be understood regarding the optimal frequency and content of disclosures including the level of explicit detail the service member divulges related to their deploymentand combat-related experiences. Such specific features likely have important implications for the potential benefits or adverse consequences of the disclosure. More disclosure does not necessary yield greater benefits for either service members or their partners. Future research could evaluate the impact of specific characteris- 
tics of the disclosure and partners' responses in this relational context.

The relation between intimate partner support and the willingness to disclose traumatic emotional experiences is likely to be bidirectional, and to involve both interpersonal as well as intrapersonal effects. In the present study, higher levels of relationship satisfaction predicted higher levels of Airmen's disclosure of deployment- and combat-related experiences. Although not assessed in this study, greater disclosure could foster subjective intimacy for both service members and their partners. For example, observational research has shown that men's vulnerable selfdisclosure in an intimate relationship significantly enhanced their own feelings of intimacy, independent of their female partners' level of empathic responding (Mitchell et al., 2008). In the same study, women's intimacy was predicted by their male partners' level of self-disclosure, but not by their own. Other diary studies have linked self-disclosure (Laurenceau, Feldman Barrett, \& Rovine, 2005; Lippert \& Prager, 2001) as well as partnerdisclosure (Laurenceau et al., 2005) to greater intimacy for both men and women in married or cohabiting relationships. The intimacy-enhancing effects of vulnerable self-disclosure for men is particularly striking, given that the majority of participants in this study $(92 \%)$ and the majority of service members generally $(86 \%$; U.S. Department of Defense, 2007) are men. Beyond its potential impact on intimacy, disclosure of deployment- and combat-related experiences may influence partners' cognitions regarding service members' reintegration difficulties and, relatedly, the partners' own emotional reactions. Moreover, evaluation of specific PTSD clusters separately, such as avoidance and numbing symptoms, may provide additional insight into the differential role of disclosure in intimate relationships.

Integration of current findings with prior empirical work suggests potential prevention and intervention strategies for service members and their partners. Considering that service members can benefit from self-disclosure of combat trauma to their partners, mental health care providers could work to enhance service members' ability to engage in self-disclosure in ways that would be most likely to elicit a positive response from their partners. Existing couple communication interventions can help inform providers of strategies most likely to elicit empathic responding (Erbes et al., 2008). Similarly, partners could be trained to use positive emotional responsiveness and active listening techniques when responding to service members' combat disclosure. Couples should be taught how to communicate effectively about service members' deployment and how it has uniquely impacted each partner (Sautter, Armelie, Glynn, \& Wielt, 2011).

The disclosure of deployment- and combat-related experiences could also be facilitated within a couple therapy context even if partners themselves cannot disclose or respond constructively on their own. With such couples, the therapist can facilitate vulnerable disclosure and model empathic responding, thereby facilitating constructive changes in partners' attributions regarding service members' postdeployment behaviors. The modification of attributions from internal (characterological) to external (combat traumarelated) may promote partners' empathic responses or reduce their own negative reactivity. Moreover, factors related to disclosure of combat-related experiences in alternative social contexts-including extended family, veterans support groups, or in therapeutic settings-warrant further investigation.
Some limitations of the present study bear noting. Data were restricted to service members' reports, and collateral data from intimate partners regarding either the Airmen's or their own functioning were not available. Because the data for mediational analyses were cross-sectional, causal linkages remain to be tested in future studies assessing PTSD symptom severity at some point subsequent to ratings of partner-support and combat-related disclosure (although results of conjoint couple therapy for PTSD by Monson and colleagues suggests the potential benefit of naturally occurring disclosure outside of the therapeutic setting). Although longitudinal studies of service members mobilized to combat theaters and assessed throughout the deployment cycle are rare, in the present longitudinal study the number of partnered service members available at $6-9$ months postdeployment who remained in the same relationship throughout the study was too small to permit evaluation of more complex mediational models incorporating additional potential mediators or moderators of partner support and PTSD symptom severity. Finally, the percentage of female service members in the present sample $(8 \%)$ was too small to examine potential sex differences suggested from previous studies comparing linkages among vulnerable disclosure, empathic responding, and relationship intimacy (e.g., Mitchell et al., 2008).

Despite these limitations, the present study is the first to document the role of disclosure of combat-related experiences as a mediating mechanism in the well-documented linkage between social support and postdeployment PTSD symptom severity in a sample of service members returning from a year-long, high-risk mission. Continued efforts should be undertaken to better understand the differential benefits of various sources and types of social support (e.g., instrumental vs. emotional) and their potential mediators and moderators. Further research should examine effects of combat disclosure on partners' psychological and relationship functioning to examine potential secondary traumatic stress responses (Dirkzwager, Bramsen, Adèr, \& van der Ploeg, 2005; Nelson Goff, Crow, Reisbig, \& Hamilton, 2009; Renshaw et al., 2011). Greater understanding of such issues as what kinds of combat-related disclosure to encourage, optimal formats for disclosure and empathic responding, and how to strengthen distressed relationships not yet conducive to vulnerable disclosures by service members struggling with traumatic experiences, will better inform prevention and intervention strategies with those men and women returning from combat deployment in their country's service.

\section{References}

Allen, E. S., Rhoades, G. K., Stanley, S. M., \& Markman, H. J. (2010). Hitting home: Relationships between recent deployment, posttraumatic stress symptoms, and marital functioning in Army couples. Journal of Family Psychology, 24, 280-288. doi:10.1037/a0019405

American Psychiatric Association. (1994). Diagnostic and statistical manual of mental disorders (4th ed.). Washington, DC: Author.

Baddeley, J. L., \& Pennebaker, J. W. (2011). A postdeployment expressive writing intervention for military couples: A randomized controlled trial. Journal of Traumatic Stress, 24, 581-585. doi:10.1002/jts.20679

Balderrama-Durbin, C., Snyder, D. K., Cigrang, J., Talcott, G. W., Tatum, J., Baker, M., . . Slep, A. (2011, November). Post-traumatic stress, partner support, and the role of combat disclosure following high-risk deployment to Iraq. In D. K. Snyder (Chair), Emerging evidence regarding post-traumatic stress disorder and relationship functioning in 
OEF/OIF combat veterans. Symposium presented at the meeting of the Association for Behavioral and Cognitive Therapies, Toronto, Canada. Benotsch, E. G., Brailey, K., Vasterling, J. J., Uddo, M., Constans, J. I., \& Sutker, P. B. (2000). War zone stress, personal and environmental resources, and PTSD symptoms in Gulf War veterans: A longitudinal perspective. Journal of Abnormal Psychology, 109, 205-213. doi: 10.1037/0021-843X.109.2.205

Brewin, C. R., Andrews, B., \& Valentine, J. D. (2000). Meta-analysis of risk factors for posttraumatic stress disorder in trauma-exposed adults. Journal of Consulting and Clinical Psychology, 68, 748-766. doi: 10.1037/0022-006X.68.5.748

Buydens-Branchey, L., Noumair, D., \& Branchey, M. (1990). Duration and intensity of combat exposure and posttraumatic stress disorder in Vietnam veterans. Journal of Nervous and Mental Disease, 178, 582-587. doi:10.1097/00005053-199009000-00005

Campbell, S. B., \& Renshaw, K. D. (2012). Distress in spouses of Vietnam veterans: Association with communication about deployment experiences. Journal of Family Psychology, 26, 18-25. doi:10.1037/a0026680

Carroll, E. M., Rueger, D. B., Foy, D. W., \& Donahoe, C. P. (1985). Vietnam combat veterans with posttraumatic stress disorder: Analysis of marital and cohabitating adjustment. Journal of Abnormal Psychology, 94, 329-337. doi:10.1037/0021-843X.94.3.329

Cigrang, J., Talcott, G. W., Tatum, J., Baker, M., Cassidy, D., Sonnek, S., . . Slep, A. (2011, November). Psychological health and intimate relationship functioning across the deployment cycle in a cohort of active-duty service members. In D. K. Snyder (Chair), Emerging evidence regarding post-traumatic stress disorder and relationship functioning in OEF/OIF combat veterans. Symposium presented at the meeting of the Association for Behavioral and Cognitive Therapies, Toronto, Canada.

Cook, J. M., Riggs, D. S., Thompson, R., Coyne, J. C., \& Sheikh, J. I. (2004). Posttraumatic stress disorder and current relationship functioning among World War II ex-prisoners of war. Journal of Family Psychology, 18, 36-45. doi:10.1037/0893-3200.18.1.36

Dirkzwager, A. J. E., Bramsen, I., Adèr, H., \& van der Ploeg, H. M. (2005). Secondary traumatization in partners and parents of Dutch peacekeeping soldiers. Journal of Family Psychology, 19, 217-226. doi:10.1037/08933200.19.2.217

Erbes, C. R. (2011). Couple functioning and PTSD in returning OIF Soldiers: Preliminary findings from the readiness and resilience in National Guard Soldiers project. In S. M. Wadsworth \& D. Riggs (Eds.), Risk and resilience in U.S. military families (pp. 47-67). New York, NY: Springer. doi:10.1007/978-1-4419-7064-0_3

Erbes, C. R., Polusny, M. A., MacDermid, S., \& Compton, J. S. (2008). Couple therapy with combat veterans and their partners. Journal of Clinical Psychology, 64, 972-983. doi:10.1002/jclp.20521

Foa, E. B., Hembree, E. A., \& Rothbaum, B. O. (2007). Prolonged exposure therapy for PTSD: Emotional processing of traumatic experiences, therapist guide. Oxford, NY: Oxford University Press.

Forbes, D., Creamer, M., \& Biddle, D. (2001). The validity of the PTSD checklist as a measure of symptomatic change in combat-related PTSD. Behaviour Research and Therapy, 39, 977-986. doi:10.1016/S00057967(00)00084-Xpp.977-986

Fredman, S. J., Monson, C. M., \& Adair, K. C. (2011). Implementing cognitive-behavioral conjoint therapy for PTSD with the newest generation of veterans and their partners. Cognitive and Behavioral Practice, 18, 120-130. doi:10.1016/j.cbpra.2009.06.007

Greenberg, N., Thomas, S. L., Iversen, A., Unwin, C., Hull, L., \& Wessely, S. (2003). Do military peacekeepers want to talk about their experiences? Perceived psychological support of UK military peacekeepers on return from deployment. Journal of Mental Health, 12, 565-573. doi: 10.1080/09638230310001627928

Hendrix, C. C., Erdmann, M. A., \& Briggs, K. (1998). Impact of Vietnam veterans' arousal and avoidance on spouses' perceptions of family life.
American Journal of Family Therapy, 26, 115-128. doi:10.1080/ 01926189808251092

Hoge, C. W., Castro, C. A., Messer, S. C., McGurk, D., Cotting, D. I., \& Koffman, R. L. (2004). Combat duty in Iraq and Afghanistan, mental health problems, and barriers to care. The New England Journal of Medicine, 351, 13-22. doi:10.1056/NEJMoa040603

Hoyt, T., Pasupathi, M., Smith, B. W., Yeater, E. A., Kay, V. S., \& Tooley, E. (2010). Disclosure of emotional events in groups at risk for posttraumatic stress disorder. International Journal of Stress Management, 17, 78-95. doi:10.1037/a0017453

Kaniasty, K., \& Norris, F. H. (2008). Longitudinal linkages between perceived social support and posttraumatic stress symptoms: Sequential roles of social causation and social selection. Journal of Traumatic Stress, 21, 274-281. doi:10.1002/jts.20334

Kazarian, S. S., \& McCabe, S. B. (1991). Dimensions of social support in the MSPSS: Factorial structure, reliability, and theoretical implications. Journal of Community Psychology, 19, 150-160. doi:10.1002/15206629(199104)19:2<150::AID-JCOP2290190206>3.0.CO;2-J

Keane, T. M., Scott, W. O., Chavoya, G. A., Lamparski, D. M., \& Fairbank, J. A. (1985). Social support in Vietnam veterans with posttraumatic stress disorder: A comparative analysis. Journal of Consulting and Clinical Psychology, 53, 95-102. doi:10.1037/0022-006X.53.1.95

King, D. W., Taft, C., King, L. A., Hammond, C., \& Stone, E. R. (2006). Directionality of the association between social support and posttraumatic stress disorder: A longitudinal investigation. Journal of Applied Social Psychology, 36, 2980-2992. doi:10.1111/j.0021-9029.2006 .00138.x

Laffaye, C., Cavella, S., Drescher, K., \& Rosen, C. (2008). Relationships among PTSD symptoms, social support, and support source in Veterans with chronic PTSD. Journal of Traumatic Stress, 21, 394-401. doi: $10.1002 /$ jts. 20348

Laurenceau, J., Feldman Barrett, L., \& Rovine, M. J. (2005). The interpersonal process model of intimacy in marriage: A daily diary and multilevel modeling approach. Journal of Family Psychology, 19, 314323. doi:10.1037/0893-3200.19.2.314

Leibowitz, R. Q., Jeffreys, M. D., Copeland, L. A., \& Noël, P. H. (2008). Veterans' disclosure of trauma to healthcare providers. General Hospital Psychiatry, 30, 100-103. doi:10.1016/j.genhosppsych.2007.11.004

Lippert, T., \& Prager, K. J. (2001). Daily experiences of intimacy: A study of couples. Personal Relationships, 8, 283-298. doi:10.1111/j.14756811.2001.tb00041.x

MacKinnon, D. P., Lockwood, C. M., \& Williams, J. (2004). Confidence limits for the indirect effect: Distribution of the product and resampling methods. Multivariate Behavioral Research, 39, 99-128. doi:10.1207/ s15327906mbr3901_4

Mitchell, A. E., Castellani, A. M., Herrington, R. L.Joseph, J. I., Doss, B. D., \& Snyder, D. K. (2008). Predictors of intimacy in couples' discussions of relationship injuries: An observational study. Journal of Family Psychology, 22, 21-29. doi:10.1037/0893-3200.22.1.21

Monson, C. M., Fredman, S. J., \& Adair, K. C. (2008). Cognitivebehavioral conjoint therapy for posttraumatic stress disorder: Application to Operation Enduring and Iraqi Freedom veterans. Journal of Clinical Psychology, 64, 958-971. doi:10.1002/jclp.20511

Muthén, L. K., \& Muthén, B. O. (2010). Mplus user's guide (6th ed.). Los Angeles, CA: Muthén \& Muthén.

Nelson Goff, B. S., Crow, J. R., Reisbig, A. M. J., \& Hamilton, S. (2007). The impact of individual trauma symptoms of deployed soldiers on relationship satisfaction. Journal of Family Psychology, 21, 344-353. doi:10.1037/0893-3200.21.3.344

Nelson Goff, B. S., Crow, J. R., Reisbig, A. M. J., \& Hamilton, S. (2009). The impact of soldiers' deployment to Iraq and Afghanistan: Secondary traumatic stress in female partners. Journal of Couple \& Relationship Therapy, 8, 291-305. doi:10.1080/15332690903246085 
Ozer, E. J., Best, S. R., Lipsey, T. L., \& Weiss, D. S. (2003). Predictors of posttraumatic stress disorder and symptoms in adults: A meta-analysis. Psychological Bulletin, 129, 52-73. doi:10.1037/0033-2909.129.1.52

Polusny, M. A., Erbes, C. R., Murdoch, M., Arbisi, P. A., Thuras, P., \& Rath, M. B. (2011). Prospective risk factors for new-onset posttraumatic stress disorder in National Guard soldiers deployed to Iraq. Psychological Medicine, 41, 687-698. doi:10.1017/ S0033291710002047

Reddy, M. K., Meis, L. A., Erbes, C. R., Polusny, M. A., \& Compton, J. S. (2011). Associations among experiential avoidance, couple adjustment, and interpersonal aggression in returning Iraqi War veterans and their partners. Journal of Consulting and Clinical Psychology, 79, 515-520. doi:10.1037/a0023929

Ren, X. S., Skinner, K., Lee, A., \& Kazis, L. (1999). Social support, social selection and self-assessed health status: Results from the veterans health study in the United States. Social Science \& Medicine, 48, 1721-1734. doi:10.1016/S0277-9536(99)00069-6

Renshaw, K. D., Allen, E. S., Rhoades, G. K., Blais, R. K., Markman, H. J., \& Stanley, S. M. (2011). Distress in spouses of service members with symptoms of combat-related PTSD: Secondary traumatic stress or general psychological distress? Journal of Family Psychology, 25, 461-469. doi:10.1037/a0023994

Renshaw, K. D., \& Campbell, S. B. (2011). Combat veterans' symptoms of PTSD and partners' distress: The role of partners' perceptions of veterans' deployment experiences. Journal of Family Psychology, 25, 953962. doi: $10.1037 / \mathrm{a} 0025871$

Renshaw, K. D., Rodrigues, C. S., \& Jones, D. H. (2008). Psychological symptoms and marital satisfaction in spouses of Operation Iraqi Freedom veterans: Relationships with spouses' perceptions of veterans' experiences and symptoms. Journal of Family Psychology, 22, 586-594. doi:10.1037/0893-3200.22.3.586

Resick, P. A., \& Schnicke, M. K. (1992). Cognitive processing therapy for sexual assault victims. Journal of Consulting and Clinical Psychology, 60, 748-756. doi:10.1037/0022-006X.60.5.748

Riggs, D. S., Byrne, C. A., Weathers, F. W., \& Litz, B. T. (1998). The quality of the intimate relationships of male Vietnam veterans: Problems associated with posttraumatic stress disorder. Journal of Traumatic Stress, 11, 87-101. doi:10.1023/A:1024409200155

Sautter, F. J., Armelie, A. P., Glynn, S. M., \& Wielt, D. B. (2011). The development of a couple-based treatment for PTSD in returning veterans. Professional Psychology: Research and Practice, 42, 63-69.

Schnurr, P. P., Lunney, C. A., \& Sengupta, A. (2004). Risk factors for the development versus maintenance of posttraumatic stress disorder. Journal of Traumatic Stress, 17, 85-95. doi:10.1023/B:JOTS.0000022614 $.21794 . \mathrm{f} 4$

Seal, K. H., Metzler, T. J., Gima, K. S., Bertenthal, D., Maguen, S., \& Marmar, C. R. (2009). Trends and risk factors for mental health diag- noses among Iraq and Afghanistan veterans using Department of Veterans Affairs health care, 2002-2008. American Journal of Public Health, 99, 1651-1658. doi:10.2105/AJPH.2008.150284

Snyder, D. K. (1997). Manual for the Marital Satisfaction InventoryRevised. Los Angeles, CA: Western Psychological Services.

Sobel, M. E. (1982). Asymptotic intervals for indirect effects in structural equations models. In S. Leinhart (Ed.), Sociological methodology 1982 (pp. 290-312). San Francisco, CA: Jossey-Bass. doi:10.2307/270723

Solomon, Z., Dekel, R., \& Zerach, G. (2008). The relationships between posttraumatic stress symptom clusters and marital intimacy among war veterans. Journal of Family Psychology, 22, 659-666. doi:10.1037/ a0013596

Tan, M. (2009). A million soldiers deployed since 9/11. Army Times Prime, 12. Retrieved from http://www.armytimes.com/news/2009/12/ army_deployments_121809w/

Ullman, S. E., Townsend, S. M., Filipas, H. H., \& Starzynski, L. L. (2007). Structural models of the relations of assault severity, social support, avoidance coping, self-blame, and PSTD among sexual assault survivors. Psychology of Women Quarterly, 31, 23-37. doi:10.1111/j.14716402.2007.00328.x

U.S. Department of Defense. (2007). Demographics 2007: Profile of the military community. Retrieved October 9, 2011 from http://www.militaryhomefront.dod.mil/12038/Project\%20Documents/MilitaryHOMEFRONT/Reports/ 2007\%20Demographics.pdf

Weathers, F. W., Huska, J. A., \& Keane, T. M., (1991). PCL-M for $D S M-I V$. Boston, MA: National Center for PTSD-Behavioral Science Division

Weathers, F. W., Litz, B. T., Herman, D. S., Huska, J. A., \& Keane, T. M. (1993, October). The PTSD Checklist (PCL): Reliability, validity, and diagnostic utility. Paper presented at the Annual Convention of the International Society for Traumatic Stress Studies, San Antonio, TX.

Whisman, M. A., Snyder, D. K., \& Beach, S. R. H. (2009). Screening for marital and relationship discord. Journal of Family Psychology, 23, 247-254. doi:10.1037/a0014476

Zimet, G. D., Dahlem, N. W., Zimet, S. G., \& Farley, G. K. (1988). The multidimensional scale of perceived social support. Journal of Personality Assessment, 52, 30-41. doi:10.1207/s15327752jpa5201_2

Zimet, G. D., Powell, S. S., Farley, G. K., Werkman, S., \& Berkoff, K. A. (1990). Psychometric characteristics of the multidimensional scale of perceived social support. Journal of Personality Assessment, 55, 610617. doi:10.1080/00223891.1990.967409

Received September 12, 2012

Revision received April 2, 2013

Accepted April 22, 2013 